\title{
Precast Concrete SMART Factory
}

\author{
Andrey Ostroukh* and Nataliya Surkova \\ Moscow Automobile and Road State Technical University (MADI), Russian Federation \\ ${ }^{*}$ Corresponding author
}

\begin{abstract}
The article proposes the concept of a Precast Concrete SMART Factory for the concrete block production. Automated Process Control System includes a set of technological equipment, information, and software for control the objects of the production line of concrete block and tile. The system is scalable and includes various local automated control systems for the preparation of concrete mixtures, molding of concrete products, warehouses of inert materials and cement, access control subsystems, and workplaces for management personnel. In accordance with the proposed concept, a complex automated system should provide an optimal level of automation for information collection and processing to form control signals and transfer them without loss and distortion to actuators in order to achieve efficient operation of the technological line for the concrete block production.
\end{abstract}

Keywords-Automated Process Control System (APCS), SMART Factory, Industrial Internet of Things (IIoT), mnemonic scheme, Product Lifecycle Management (PLM), Enterprise Resource Planning (ERP)

\section{INTRODUCTION}

At present, the manufacture of concrete block is one of the largest industrial branches, in which huge factories and factories, as well as private manufacturing enterprises, operate. This development of the industry is justified, because paving slabs are products that are in demand by the consumer.

Producers are offered a rich and well-thought-out assortment of not only paver, but also curbs, spillways, steps, etc.

The production of the precast concrete requires minimal human operator involvement, as modern production is fully automated. The equipment for making concrete blocks and paving slabs can differ both externally and by characteristics, but the essence of the process does not change.

Manufacturing high-quality concrete block is impossible without the use of modern technological equipment and the introduction of automated control systems for technological processes production $[1-6]$.

\section{CONCEPT OF THE CONCRETE BATCHING PLANT AUTOMATION}

In accordance with the methodology of systems engineering work on the creation of concrete plant automation will divide into stages and steps.

At the first stage we formulate the goal of the system [7 11]. APCS concrete plant is designed for effective control and management process, from submission of materials from warehouses and ending with the delivery of the concrete mix to consumers. The purpose of control - increased efficiency, rhythm and quality of production, the timely provision of the necessary number of consumers mixtures settings.

In the second stage of the system analysis to delimit the system under study. Specifies that the system should include the management of the following processes: supply of materials from warehouses in capacity over the bunker separating dosing concrete mixture, issuance and delivery of ready-mixed concrete in the molding stations. Molding and other areas that consume the concrete, as well as rail and road transport, delivering the components of concrete warehouses, are not included in the system and can be attributed to the environment. It is assumed that in the operation of the system receives the orders for the concrete mix (with points of consumption), and the components of the concrete mix (warehouse cement and aggregates).

Thus, the external environment influences on the system. The influence of the external environment is neglected.

As a result, the primary structuring elements stand out the process to be automated management, as well as inputs and outputs that connect the system under consideration and the environment.

In the third stage of system analysis develop a mathematical model of the system. At this stage, limited to image and verbal description of subsystems and communication function.

Given the natural structure of the process, we conduct its decomposition into sub-processes (FIGURE I).

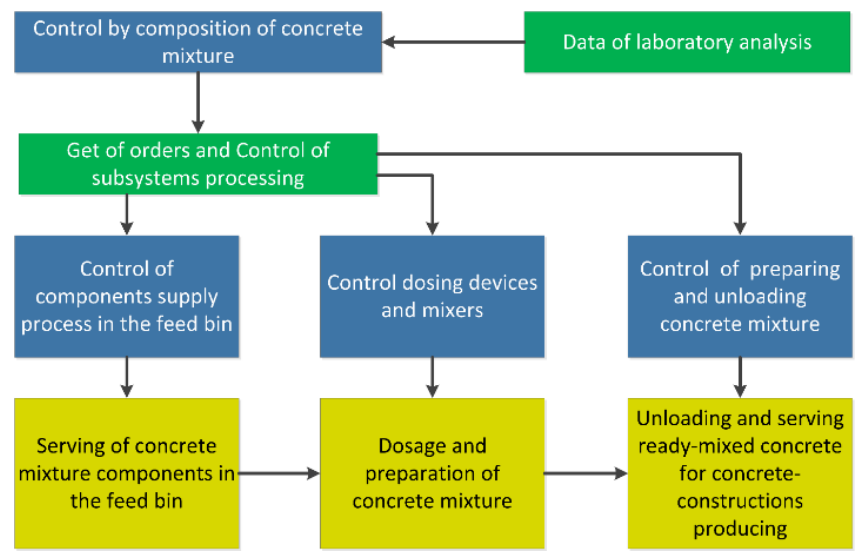

FIGURE I. CONTROL TASKS FOR CONCRETE BATCHING PLANT 
In accordance with the decomposition process in the subdecomposed management tasks into subtasks (difficulty level decision makers).

The overall objective of the control process as a whole is divided into a series of consistently solve simpler problems (see FIGURE I). First, on the basis of laboratory analysis established percentages of components in concrete mixtures of different brands, taking into account humidity and debris aggregates, cement activity and so on. The results of this task are the initial data for the solution of coordination of subsystems in accordance with the orders for concrete mix, coming from environment. Based on the data queue of orders and results of solving the problem of the control structure, defined job dispensers and mixers, chain selected vehicles, delivering the finished concrete mixture to the consumer, supply bins are determined to be downloaded.

Further, preliminary design is carried out and the choice of the technical means control system (FIGURE II).

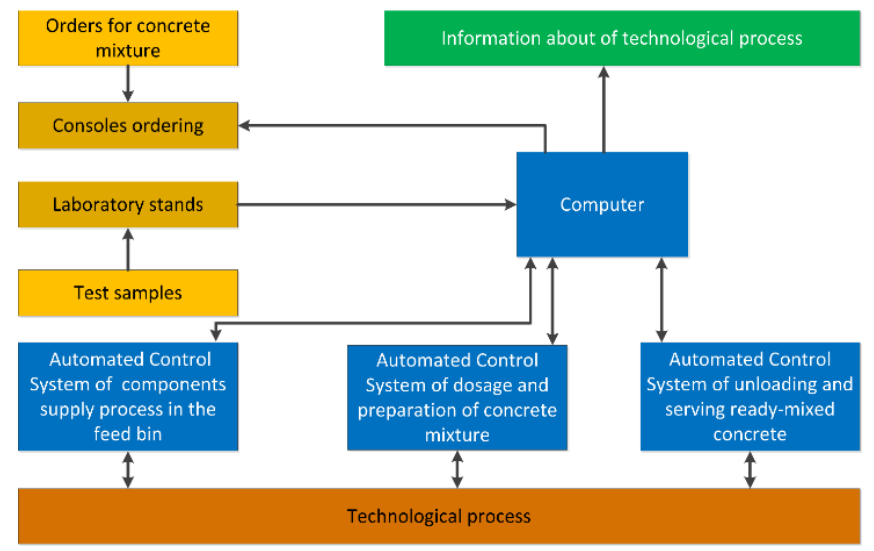

FIGURE II. MODEL ACS FOR CONCRETE PLANT

Based on these stages of systems analysis work is distributed among individual performers, compiled schedules for completion of design and research works.

In the future for a number of sub-systems are drawn up more detailed mathematical models. In this transition function, outputs, binding functions are described in the form of mathematical expressions, which allows you to explore a variety of control algorithms by numerical simulation on a computer.

At receipt in the concrete component weighbridge tracking error mass change of material in the hopper of the dispenser because of the transient is large.

After closure of the dosing process and damping of transient weight of each component can be measured with greater accuracy. If it turns out that the components of the vector of percentage deviation is beyond a certain tolerance range, select the type of component and the corresponding dispenser dosing. After the implementation of the selected dosing procedure is repeated until the line is in principle the interactions vector percentage deviations will not be in the predetermined region.

\section{MultileVel StRucture OF THE CONTROL SySTEM CONCRETE PLANT}

Concrete plant control system has three-level structure and may include multiple geographically distributed plants connected into one technological system integrated into the enterprise management system (FIGURE III).

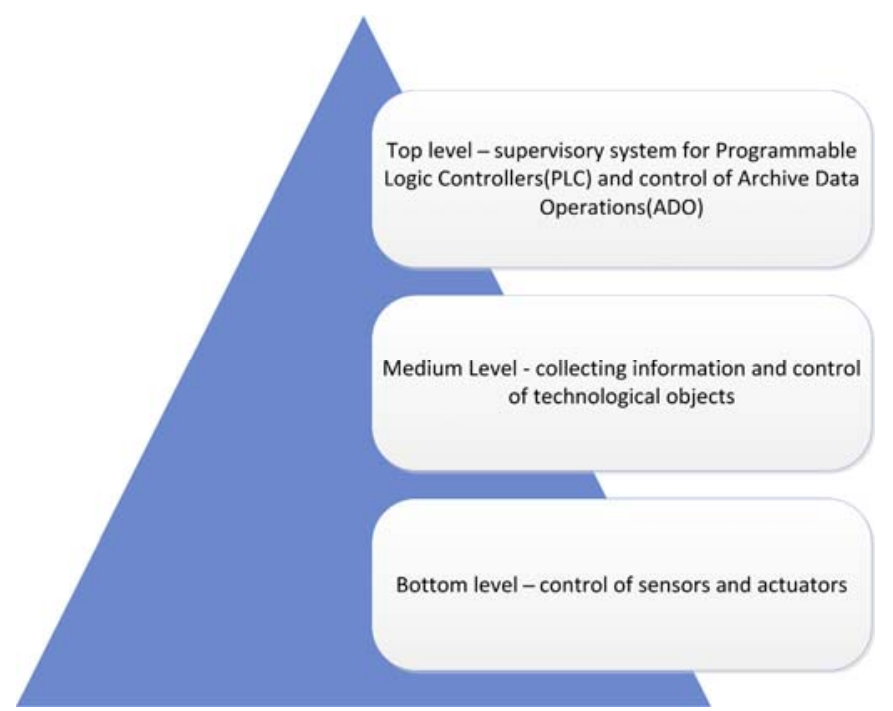

FIGURE III. THREE-LEVEL MANAGEMENT STRUCTURE CONCRETE PLANT

The complex may consist of the following subsystems:

- $\quad$ concrete plant;

- dispatching service;

- laboratory;

- $\quad$ hydrothermal treatment;

- $\quad$ weight management;

- $\quad$ warehouses of inert materials and cement;

- targeted distribution of concrete, access control systems;

- employment of administrative staff.

The database of each production associated with enterprise management system and allows you to share information in real time.

\section{SMART FACTORY CONCEPT}

SMART Factory is defined as an enterprise that, on the basis of context-aware knowledge, helps people and mechanisms perform their tasks. (FIGURE IV). 


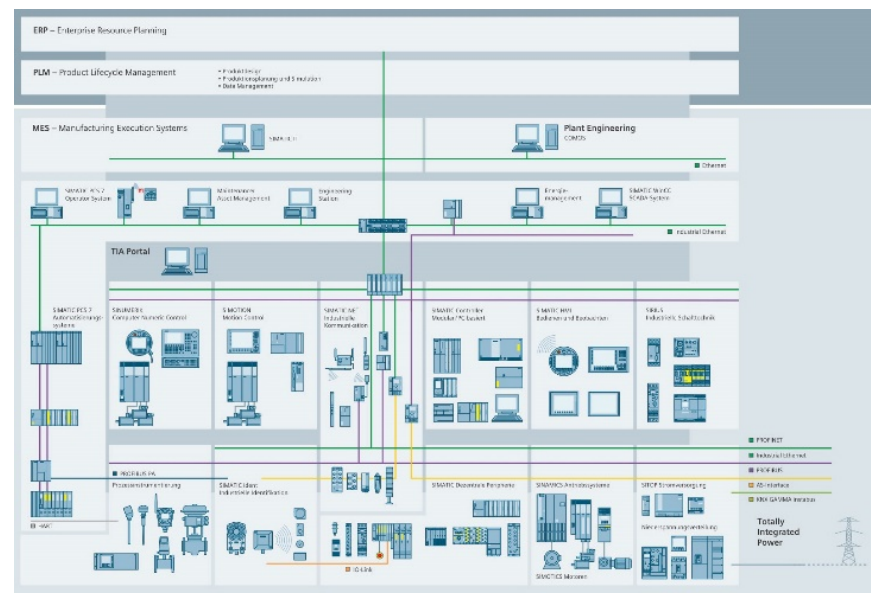

FIGURE IV. SIEMENS SMART FACTORY

This is achieved with the help of background-active systems, as well as taking into account contextual information in their work, for example, the position and status of the object. These systems perform their tasks on the basis of information coming from the physical or virtual world. Information from the physical world is, for example, the position or state of the instrument, and information from the virtual world can be electronic documents, blueprints or simulation models.

SMART Factory can be used for industries that are characterized by:

- complexity and dynamics of ongoing processes;

- $\quad$ uncertainty of supply and demand;

- $\quad$ individual approach to each manufactured product;

- frequent updates to the product range;

- $\quad$ production of small series of goods.

All this requires department heads to be highly responsive in making decisions and adapting plans when unforeseen events occur in real time. SMART Factory integrates existing Product Lifecycle Management (PLM) and Enterprise Resource Planning (ERP) with the ability to adapt and adapt plans for real-time events, for example, from customers or from other control systems, from automatic line sensor sensors, tablet masters or touch screen workers to eliminate downtime and A shortage of resources or highly skilled workers. In the process of exploitation, a knowledge base is created about production processes, products and materials, equipment and workers to ensure an individual approach to each order or resource. This allows you to make plans more precise and executable at any events, such as the occurrence of a highpriority order, equipment failure, delays in the supply of materials, etc.

Automated Process Control System to be designed on the basis of Siemens SIMATIC equipment, which includes modern industrial Programming Logical Controllers S7-1500, industrial IPC computers, TP touch screens and ITP1000 tablet computers, using industrial network routers and wireless access points SCALANCE. (FIGURE V).

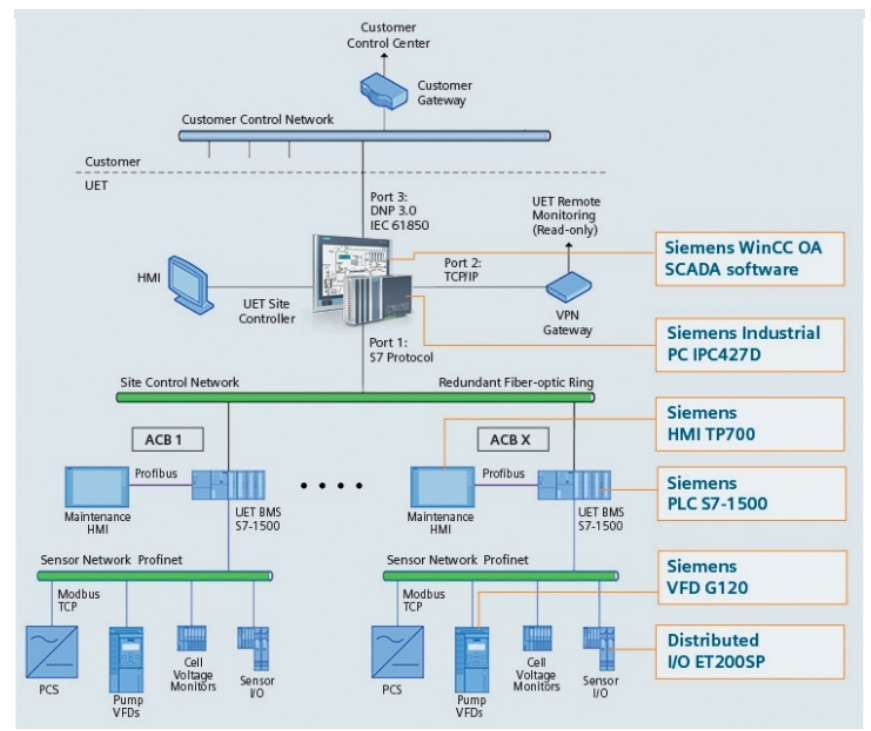

FIGURE V. LOGICAL STRUCTURE OF SIEMENS PROFINET

\section{Precast Concrete Batching Control System}

In the production of concrete paver and block, planetary concrete mixers are used, which have some design features. It is equipped with a skip, must have a cement dispenser and the ability to add coloring additives.

Example of mnemonic scheme of concrete batching control system for a concrete batching plant with planetary concrete mixers implemented on the basis of SCADA [12] (FIGURE $\mathrm{VI})$.

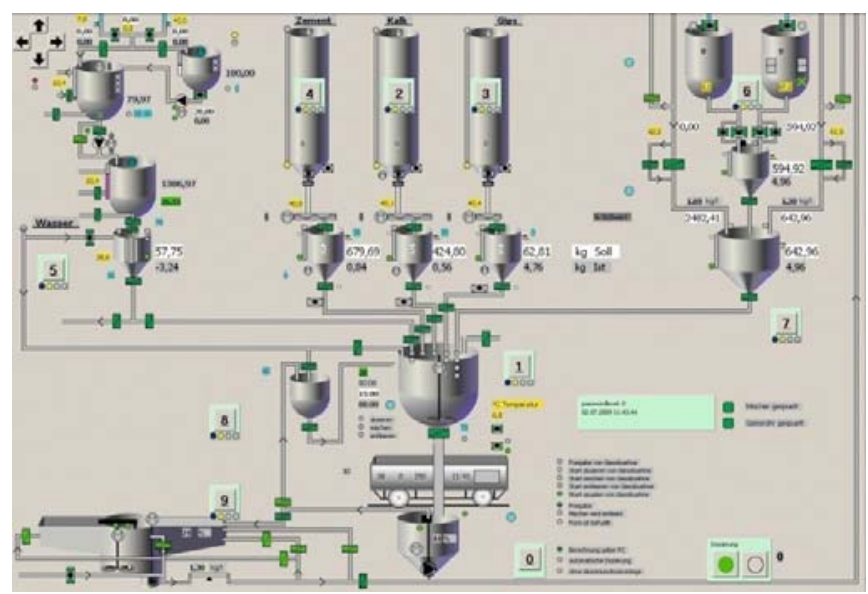

FIGURE VI. MNEMONIC SCHEME OF CONCRETE BATCHING CONTROL SYSTEM

This control system with a personal industrial computer provides dosing of individual components according to a preset recipe. Control is equipped with a visualization system, statistical programs, a printer, remote maintenance, etc.

Using the menu bar buttons, you can get more detailed information on each of the nodes and organize work with the lists of emergency and technological messages, which allows the operator to fully control the operation of the system, 
monitor the failures of technological equipment and prevent emergencies.

All actions of the operator and failures of the technological equipment are recorded. In addition, a database of dosing results for each order is formed, with information on the order execution time and the quantity of the dosed out raw materials.

In the event of failure of the operator station, a spare control channel is provided from the operator panel (console).

The system includes several flexibly adjustable parameters installed in the engineering settings window, with which you can fine-tune the various delay times, weight thresholds, dosing parameters, and so on.

\section{CONCLUSION}

Further research and search for new solutions for the automation of industrial enterprises in the SMART Factory concept and their subsequent introduction, including the production of concrete block, are needed.

This will increase the efficiency in making decisions and adapting plans in the event of unforeseen events in real time, as well as significantly improve the quality of the shipped product and reduce the percentage of rejects due to increased accuracy of dosing of the components of the concrete mixture and its preparation time, automatic control over the molding process.

The accumulation of a knowledge base on consumable raw materials and materials for different time periods will allow the introduction of intellectual analysis to control the turnover of raw materials, materials and finished products in the enterprise.

Expected increase in labor productivity and technological discipline, due to the exclusion of the operator's labor by replacing it with cyberphysical systems and automatic logging of events.

\section{REFERENCES}

[1] Ostroukh A.V., Nedoseko I.V., Pudovkin A.N., Nuruev Y.E. 2015 Development of the Automated Control System for Concrete Plant with Two Units Concrete Mixing. International Journal of Applied Engineering Research. 10(17): 37792-37798.

[2] Wai Ph.A., Ostroukh A.V. 2014. Development of simulation model mixed system in the AnyLogic software. International Journal of Advanced Studies (iJAS). 4(4): 48-53. DOI: 10.12731/2227-930X-20144-2.

[3] Kabir M.R., Ismoilov M.I., Ostroukh A.V. 2014. Automated Control Systems Concrete Plant. Automation and Control in Technical Systems. No 3 (11). C. 178-190. DOI: 10.12731/2306-1561-2014-3-17.

[4] Kabir M.R., Ismoilov M.I., Ostroukh A.V. 2014. System Approach to the Design Process ACS Concrete Mixing. Automation and Control in Technical Systems. No 3 (11). C. 191-200. DOI: 10.12731/2306-15612014-3-18.

[5] Ostroukh A.V., Aysarina A. A. 2015. Development of Automated Control Systems for Concrete Mixing Plants Based Twin-Shaft Mixer. Automation and Control in Technical Systems. No 1. C. 51-59. DOI: 10.12731/2306-1561-2015-1-7.

[6] Ostroukh A.V., Nedoseko I.V., Pudovkin A.N., Nuruev Y.E. 2015 Development of the Automated Control System for Concrete Plant with Two Units Concrete Mixing. International Journal of Applied Engineering Research. 10(17): 37792-37798.

[7] Ostroukh A.V., Bashmakov I.A., Surkova N.E. 2014. Process Model of the Technology of Concrete Mixtures Transportation by Road. World
Applied Sciences Journal (WASJ). 31(4): 500-507. DOI: 10.5829/idosi.wasj.2014.31.04.333.

[8] NIKOLAEV A.B., VASUHOVA S.A., OSTROUKH A.V. AUTOMATED SYSTEMS AND INDUSTRIAL ROBOTS REMOTE CONTROL // SGEM2014 Conference Proceedings, ISBN 978-6197105-10-0 / ISSN 1314-2704, June 19-25, 2014, Vol. 1, 51-56 pp. DOI: 10.5593/SGEM2014/B21/S7.007.

[9] Ostroukh A.V., Mezencev K.N., Krasnyanskiy M.N., Punam J., Surkova N.E. SIMULATED OPERATION OF THE COMPUTER NETWORK // SGEM2015 Conference Proceedings, ISBN 978-619-7105-34-6 / ISSN 1314-2704, June 18-24, 2015, Book2 Vol. 1, 299-306 pp. DOI: 10.5593/SGEM2015/B21/S7.037.

[10] Ostroukh A.V., Krasnyanskiy M.N., Obukhov A.D., Karpov S.V., Dedov D.L. DEVELOPMENT OF AUTOMATED INFORMATION SYSTEMS FOR MONITORING OF INTELLECTUAL ACTIVITY RESULTS // SGEM2015 Conference Proceedings, ISBN 978-619-710534-6 / ISSN 1314-2704, June 18-24, 2015, Book2 Vol. 1, 101-108 pp. DOI: 10.5593/SGEM2015/B21/S7.014.

[11] OSTROUKH A.V., NIKOLAEV A.B., SURKOVA N.E. KRASNYANSKIY M.N. DEVELOPMENT OF LABORATORY WORK FOR REMOTE ACCESS LABORATORY // SGEM2014 Conference Proceedings, ISBN 978-619-7105-10-0 / ISSN 1314-2704, June 19-25, 2014, Vol. 1, 119-126 pp. DOI: 10.5593/SGEM2014/B21/S7.016.

[12] Salniy A.G., Kukharenko V.N., Nikolaev A.B., Ostroukh A.V. 2013. General principles of SCADA-systems. Automation and Control in Technical Systems. (2): 8-12. 